\title{
CLINICAL PROFILE OF CHRONIC RHINOSINUSITIS: A STUDY IN CENTRAL INDIA
}

KEY WORDS: Chronic Rhinosinusitis, polyps, CRSsNP.

\section{Tanvi Rekhade}

A.Z. Nitnaware

Seema Patel*

\section{R. T. Pawar}

\section{Ashish Keche}

Resident, Dept. of ENT, GMC Nagpur, Maharashtra -440003.

Professor and Head, Dept. of ENT, GMC Nagpur, Maharashtra -440003. Associate Professor, Dept. of ENT, GMC Nagpur, Maharshtra -440003. *Corresponding Author

Assisstant Professor, Dept. of ENT, GMC Nagpur, Maharashtra -440003.

Assisstant Professor, Dept. of ENT, GMC Nagpur, Maharshtra -440003.

Chronic Rhinosinusitis (CRS) has heavy implications on the quality of life and has a prevalence of about $46.1 \%$ in northern India with similar pattern across the country. This research has been undertaken to study the presentation and causative factors for CRS in central India. Data of 100 patients diagnosed as CRS was studied. Patients presented with nasal obstruction and nasal discharge at large. Nasal polyps were seen in $37 \%$ cases. The most common associated etiopathological factor was anatomical obstruction due to deviated nasal septum.

\section{INTRODUCTION}

Almost a decade after the guidelines for its diagnosis are formulated, Chronic Rhinosinusitis (CRS) remains an underdiagnosed entity. As per the European position paper on Rhinosinusitis and Nasal Polyposis: 2012 (EPOS 2012), rhinosinusitis is characterized by atleast one or both primary symptoms viz. nasal blockage, nasal discharge with atleast one additional symptom viz. facial pain, hyposmia/anosmia ${ }^{1}$. It is supported by objective finding of endoscopy or radiology. Duration of more than 12 weeks is needed to label it as chronic. It is broadly categorized as CRS with nasal polyposis (CRSwNP) or without polyposis (CRSsNP) based on presentation.

The prevalence of CRS is $46.1 \%$ in northern India and the pattern is same throughout the Indian subcontinent ${ }^{2}$.Owing to nonspecific symptoms, CRS is often misdiagnosed as prodrome or flu itself, thus is neglected. If not diagnosed and treated optimally it may affect the quality of life thereby hampering the overall progress of an individual.

This study has been undertaken, to understand etiopathog enesis and presentation of CRS in central India.

\section{METHODS}

This descriptive cross sectional study was carried out at the Department of ENT, GMC Nagpur from June 2018 to December 2020. A total of 100 patients diagnosed as CRS as per EPOS 2012 guidelines and willing to consent for the study were included. Patients with complications of CRS viz. orbital cellulitis, osteomyelitis, meningitis etc , those with systemic causes of CRS, fungal rhinosinusitis, malignancy and pregnant females were excluded from the study.

Detailed history and clinical examination data of these patients was recorded. Relevant blood investigation, radiological (CT PNS) investigations and endoscopic examination were carried out. When needed histopatho logical and microbiological examination of intranasal tissue was done.

\section{OBSERVATION AND RESULT}

The patients registered in this study were more from the urban areas i.e $57(57 \%)$ than rural areas i.e. $43(43 \%)$.They belonged to the age group 12-75 yrs with maximum cases being in age group 31-40yrs i.e 28(28\%) followed by $21-30$ yrs i.e $25(25 \%)$ (Fig 1). The subgroups showed similar distribution of patients over the age groups. Most common age of presentation was 21-30yrs i.e $19(30.16 \%)$ patients in CRSsNP and 31-40yrs for CRSwNP with 10(27.03\%) patients.
Percentage distribution of patients in the age groups

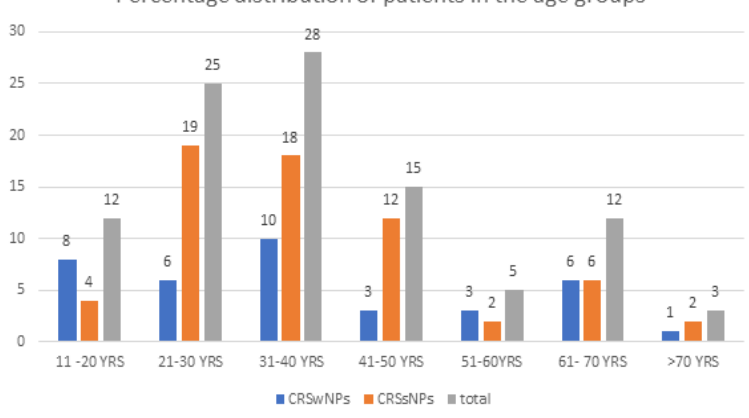

Fig 1: Age wise distribution $(n=100)$

Males were $64(64 \%)$ and females were $36(36 \%)$ with male female ratio of 1.78:1. The most common complaint in patients with CRSwNPs ( $n=37$ ) was nasal obstruction seen in all $37(100 \%)$ patients followed by nasal discharge in $30(81.08 \%)$, facial fullness in $14(37.84 \%)$ and olfactory disturbances in 11 (29.73\%). Amongst the patients of CRSsNPs $(n=63)$ nasal obstruction and nasal discharge were the commonest seen in $59(93.65 \%)$ patients followed by facial fullness in $25(39.68 \%)$ and olfactory disturbances seen in $9(14.29 \%)$. Other concomitant symptoms of itching, watering of eyes, dental pain, recurrent sore throat, snoring, ear complaints, halitosis, chest fullness and headache were noted. In the ongoing COVID-19 pandemic, 2 post covid cases also presented with exacerbation of symptoms of CRS after covid infection.

Commonest examination finding was nasal discharge documented in $72(72 \%)$ patients followed by congested nasal mucosa in $42(42 \%)$. Nasal polyps were documented in 37 (37\%) cases. Endoscopy and radiological (CT PNS) examination findings were studied. Accordingly maxillary was commonest sinus to be involved in 94 (94\%) cases followed by anterior ethmoids in 57 (57\%), frontal in 30(30\%), posterior ethmoids in $12(12 \%)$ and sphenoid in $8(8 \%)$. Various anatomic variations were noted in $73(73 \%)$ patients. The most common anatomic variation that was documented in this study was deviated nasal septum (DNS) seen in about 62 $(62 \%)$ patients. Other anatomical variations noted were concha bullosa, enlarged bulla, paradoxical middle turbinate, pneumatised uncinate, haller cell, agger nasi cell, hypoplastic maxilla and accessory ostium (table 1). 


Table 1 : Anatomic Variations (n=100)
\begin{tabular}{|l|l|l|}
\hline $\begin{array}{l}\text { Sr. } \\
\text { No. }\end{array}$ & $\begin{array}{l}\text { Anatomic variation based on } \\
\text { endoscopy and radiology } \\
\text { findings }\end{array}$ & $\begin{array}{l}\text { Percentage of patients } \\
\text { with the findings (total } \\
\text { number) }\end{array}$ \\
\hline 1 & Deviated nasal septum (DNS) & $49 \%(49)$ \\
\hline 2 & DNS + Concha bullosa & $6 \%(6)$ \\
\hline 3 & Concha bullosa & $2 \%(2)$ \\
\hline 4 & DNS + Hypoplastic maxilla & $2 \%(2)$ \\
\hline 5 & Accessory ostium & $2 \%(2)$ \\
\hline 6 & Enlarged bulla & $1 \%(1)$ \\
\hline 7 & $\begin{array}{l}\text { Enlarged bulla + Accessory } \\
\text { ostium }\end{array}$ & $1 \%(1)$ \\
\hline 8 & $\begin{array}{l}\text { DNS + Paradoxical middle } \\
\text { turbinate }\end{array}$ & $1 \%(1)$ \\
\hline 9 & $\begin{array}{l}\text { DNS + Paradoxical middle } \\
\text { turbinate + Enlarged bulla }\end{array}$ & $1 \%(1)$ \\
\hline 10 & $\begin{array}{l}\text { DNS + Pneumatised uncinate + } \\
\text { Enlarged bulla }\end{array}$ & $1 \%(1)$ \\
\hline 11 & DNS + Enlarged bulla & $1 \%(1)$ \\
\hline 12 & DNS + Haller cell & $1 \%(1)$ \\
\hline 13 & $\begin{array}{l}\text { Concha bullosa + Pneumatised } \\
\text { uncinate + Agger nasi }\end{array}$ & $1 \%(1)$ \\
\hline 14 & Paradoxical middle turbinate & $1 \%(1)$ \\
\hline 15 & $\begin{array}{l}\text { Paradoxical middle turbinate + } \\
\text { Pneumatised uncinate }\end{array}$ & $1 \%(1)$ \\
\hline 16 & Pneumatised uncinate & $1 \%(1)$ \\
\hline 17 & Haller cell & $1 \%(1)$ \\
\hline
\end{tabular}

Etiopathological correlation was deduced based on clinical history, examination and blood investigations. The associations were found to be mostly multifactorial (Fig 2). Most frequent association was anatomical obstruction + allergy seen in $31(31 \%)$ patients followed by anatomical obstruction alone in $26(26 \%)$ and anatomical obstruction + infection seen in $11(11 \%)$. Only allergy was documented in $11(11 \%)$ patients, only infection in $10(10 \%)$, anatomical obstruction + history of trauma in $3(3 \%)$, anatomical obstruction + GERD in $2(2 \%)$, use of long term nasal decongestants in $2(2 \%)$ and GERD alone in $1(1 \%)$. No cause was identified in $3(3 \%)$ patients. Documented in $73(73 \%)$ patients overall, anatomical obstruction was most prevalent.

\section{Percentage of etiopathological factors $(n=100)$}

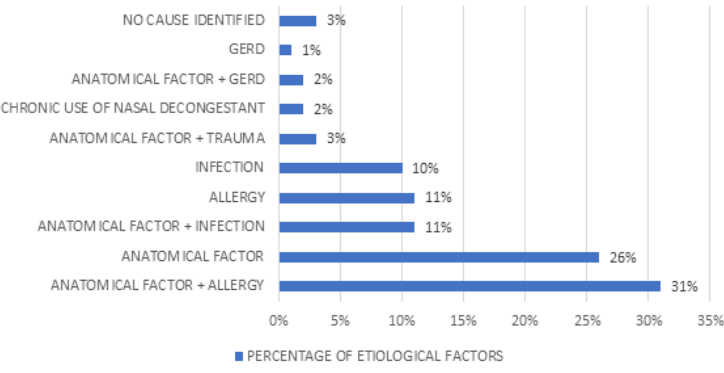

\section{Fig 2: Etiopathological correlation $(n=100)$}

\section{DISCUSSION}

Chronic Rhinosinusitis is a disease characterized by inflammation of the mucosa of nose and paranasal sinuses for a consecutive period of atleast 12 weeks. It is an extremely prevalent disorder with significant impact on quality of life of people. The prevalence of CRS ranges from $12 \%$ in USA to $7.12 \%$ in korea to $10.9 \%$ in Europe ${ }^{3}$.

In this study more patients belonged to the urban areas of central India i.e. $57 \%$ as compared to rural area. A study conducted by Arun KTM et al in northern India also showed that CRS was seen more in urban population ${ }^{4}$.

In the present study the most common age group was 31-40 yrs $(28 \%)$ followed by $21-30$ yrs (25\%). Similar distribution was found in studies by Modgil $\mathrm{N}^{5}$ where $38 \%$ cases belonged to age $<40 \mathrm{yrs}$ and Supraneni $\mathrm{H}$ et $\mathrm{al}^{6}$ where $25 \%$ cases belonged to age group 16-30yrs while $22 \%$ belonged to $31-45$ yrs.

Male gender (64\%) preponderance was seen in our study with Male:female ration of 1.78:1. Similar male preponderance was documented in the studies by Garg D et $\mathrm{al}^{7}$ and Lohiya $\mathrm{S}$ et $\mathrm{al}^{8}$.

The commonest presenting symptom in our study was nasal obstruction seen in 100\% patients with CRSwNP and 93.65\% patients with CRSsNP. This was followed closely by nasal discharge seen in $81.08 \%$ patients with CRSwNP and $93.65 \%$ patients with CRSsNP. Nasal discharge was most common sign in our study seen in $72 \%$ patients followed by nasal mucosa congestion in $42 \%$. Garg D et al documented nasal discharge as the most common symptom seen in $100 \%$ patients ${ }^{7}$. Lohiya $\mathrm{S}$ et al reported nasal obstruction and discharge as the commonest symptoms and nasal discharge as the commonest $\operatorname{sign}^{8}$.

Of the different anatomical variations that we came across in our study, DNS was most persistent seen in $62 \%$ patients followed by concha bullosa in 8\%.DNS was also the most common anatomical variation seen in study by Lohiya $\mathrm{S}$ et $\mathrm{al}^{8}$. A study conducted by Pawar S et al also showed similar association with DNS and concha bullosa being common anatomical variarion ${ }^{9}$.

The most common etiology in our study was anatomical obstruction $(73 \%)$ and allergy $(42 \%)$ followed by infections $(22 \%)$ i.e dental infection (14\%), tonsillitis, adenoid inflammation, COVID-19 infections. In the study by Supraneni $\mathrm{H}$ et $\mathrm{al}^{5}$, infection was documented as most common (26\%). In case of the patients who reported with increased severity of symptoms after recovering from covid 19 infections, covid was assumed to be the cause for exacerbation due to the temporal association of the disease with the infection. However a study conducted by Wang $\mathrm{H} \mathrm{et} \mathrm{al}^{10}$ in this regard found no correlation at all. More research in this direction is needed to be able to achieve certain clarity.

\section{CONCLUSION}

CRS was reported more from urban population of central India. The most common presenting age group was 31-40 yrs with male predominance. The most frequent presenting complaints were nasal obstruction and discharge. Common signs on examination were nasal discharge and nasal mucosa congestion. DNS was a persistent anatomical variation associated with majority of cases. The etiopathology of CRS is multifactorial. The various etiopathological factors found in our study were anatomical obstruction, allergy, dental infection, chronic tonsillitis, GERD, chronic use of nasal decongestant.

\section{REFERENCES}

1. Fokkens WJ, Lund VJ, Mullol J, et al. EPOS 2012: European position paper on rhinosinusitis and nasal polyps 2012. A summary for otorhinolaryngologists. Rhinology.2012;50(1):1-12.doi:10.4193/Rhino50E2

2. Khan AR ,Siddiqui F. Regional prevalence of different types of sinusitis at a tertiary care centre in Northern India. Int L Otorhinolaryngol Head Neck Surg 2020 May;6(5):969-973.

3. Beule A. Epidemiology of chronic rhinosinusitis, selected risk factors, comorbidities, and economic burden. GMS Curr Top Otorhinolaryngol Head NeckSurg.2015;14:Doc11.

4. Arun KTM, Singhal SK, Dass A, Chander J, Pol SA, Gupta N, et al. To Evaluate Clinico - Microbiological Profile in Chronic Rhinosinusistis: A Prospective Cohort Study in North India. J Otolaryngol Rhinol. 2020;6:084. doi.org/10.23937/2572-4193.1510084

5. Modgil N. Evaluation of the medical and surgical management of chronic rhinosinusitis with polyposis. International Journal Of Otorhinolaryngology And Head And Neck Surgery.201 6;2 (3):120-124.

6. Surapaneni H, Sisodia S. Aetiology, diagnosis and treatment of chronic rhinosinusitis: a study in a teaching hospital in Telangana. International Journal Of Otorhinolaryngology And Head And Neck Surgery. 201 6;2(1):14-17.

7. Garg D, Kamble A, Puttewar M. Demographic and clinical profile of chronic rhinosinusitis patients in a rural based tertiary hospital. International Journal 
PARIPEX - INDIAN JOURNAL OF RESEARCH | Volume - 10 | Issue - 04 |April - 2021 | PRINT ISSN No. 2250 - 1991 | DOI : $10.36106 /$ paripex

OfOtorhinolaryngology And Head And Neck Surgery.2019; 5(5):1172-1178.

8. Lohiya SS, Patel SV, Pawde AM, Bokare BD, Sakhare PT. Comparative Study of

Diagnostic Nasal Endoscopy and CT Paranasal Sinuses in Diagnosing Chronic Rhinosinusitis. Indian J Otolaryngol Head Neck Surg. 2016 Jun;68(2):224-9.

9. Shephali S Pawar, Saksham Bansal. CT anatomy of paranasal sinuses corelation with clinical sinusitis. International Journal of Contemporary Medical Research 2018;5(4):Dl-D3.

10. Wang H, Song J, Pan L, YaoY, DengYK, Wang ZC, Liao B, Ma J, He C, Zeng M, Liu Z . The characterization of chronic rhinosinusitis in hospitalized patients with COVID-19.J Allergy Clin Immunol Pract. 2020 Nov-Dec;8(10):3597-3599.e2. 